\title{
Retrospective study of maternal and neonatal outcome in second stage lower segment caesarean section in a tertiary hospital
}

\author{
M. P. A. Sailakshmi, Vidhyadhare G. S.* \\ Department of Obstetrics and Gynecology, Raja Rajeswari Medical College and Hospital, Bangalore, Karnataka, India \\ Received: 25 July 2020 \\ Revised: 16 October 2020 \\ Accepted: 17 October 2020 \\ *Correspondence: \\ Dr. Vidhyadhare G. S., \\ E-mail: vidhyadhare.gs@gmail.com \\ Copyright: (C) the author(s), publisher and licensee Medip Academy. This is an open-access article distributed under \\ the terms of the Creative Commons Attribution Non-Commercial License, which permits unrestricted non-commercial \\ use, distribution, and reproduction in any medium, provided the original work is properly cited.
}

\begin{abstract}
Background: Caesarean section at second stage are increasing and are associated with significant maternal morbidity. The overall caesarean section rates are also increasing from last two decades.

Methods: A retrospective study conducted in Department of Obstetrics and Gynaecology, Raja Rajeswari Medical College and Hospital, Bangalore from January 2018 to July 2019. Second stage LSCS were analysed in terms of indications, intraoperative and post-operative complications, neonatal morbidity.

Results: In our hospital during study period there were 2639 deliveries and total number of LSCS 1146 (43.42\%) and caesarean section rate was 35-45\% and second stage LSCS $60(5.23 \%)$.

Conclusions: Second stage LSCS associated with more number of maternal and neonatal morbidity. Adequate clinical exposure and appropriate training are essential for safe performance in second stage LSCS.
\end{abstract}

Keywords: Intraoperative complications, Neonatal morbidity, Second stage LSCS

\section{INTRODUCTION}

Second stage of labour begins with complete dilatation of cervix and ends with fetal delivery. ${ }^{1}$ Median duration is approximately 50 minutes in Primi and 20 minutes in multi. As the duration of second stage increases the lower segment become oedematous, stretched and thinned out.

Deeply impacted fetal head on to pelvis makes the procedure technically difficult and associated with operative complications such as extension of incision, broad ligament hematoma, bladder injury. ${ }^{2}$ The rate of second stage LSCS are increasing. ${ }^{3}$ LSCS at full dilatation of cervix adds more risk to mother such as haemorrhage, need of blood transfusion, wound infection and long hospital stay, delayed extraction causes fetal morbidity. ${ }^{4,5}$

As per NICE guidelines 2014, second stage is divided into two phases: ${ }^{6}$

\section{First phase/pelvic phase/passive phase}

Begins with full dilatation of cervix and ends after involuntary or spontaneous bearing down efforts, characterized by rapid descent of presenting part. Utero placental perfusion and fetal oxygenation does not deteriorate.

\section{Second phase/perineal phase/active phase}

Begins with appearance of bearing down efforts and ends with delivery of fetus. Utero placental perfusion and fetal oxygenation deteriorates if there is prolongation of this phase.

\section{Abnormal descent is of two types}

Protracted descent

If descent of presenting part is $<1 \mathrm{~cm}$ in Primi and $<2 \mathrm{~cm}$ in multi. 


\section{Arrest in descent}

No descent of presenting part for more than one hour.

Second stage may prolong because of CPD, abnormal fetal position, poor expulsive efforts resulting from analgesia and sedation, maternal exhaustion. ${ }^{6}$

To study the second stage LSCS in terms of in terms of indications, intraoperative and post-operative complications, neonatal morbidity.

\section{METHODS}

This was a retrospective study conducted at Department of OBG Raja Rajeshwari Medical College and Hospital Bangalore from January 2018 to July 2019. All second stage LSCS done during this period were taken.

The total number of deliveries were 2639 and total number of LSCS were $1146(43.42 \%)$. Total number of second stage LSCS were 60 (5.23\%). Sample size was 60.

\section{Inclusion criteria}

Primi and multiparous pregnant women of age 22-35 years. Both spontaneous progress and induced with PGE2 were included.

\section{Exclusion criteria}

Preterm, post term, PROM, chorioamnionitis, GDM, T2DM, cardiac disease, respiratory distress, severe anaemia, obesity, seropositive cases.

\section{Statistical analysis}

Statistical analysis was performed using SPSS 22.

\section{RESULTS}

Most common indications for second stage LSCS were fetal distress- 20 (33\%); arrest in descent- $15(24 \%)$; deflexed head- 11 (18\%); DTA- 9 (15\%); occipito posterior- 5 (11\%) (Figure 1).

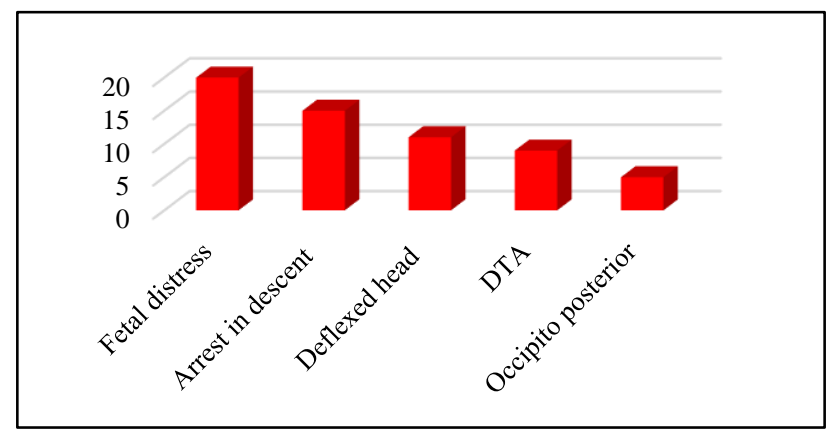

Figure 1: Common indications for second stage LSCS.

\section{Operative complications}

\section{Intraoperative complications}

Among intra operative complications post-partum haemorrhage was $12(20 \%)$, uterine angle extension was $4(6.6 \%)$ and $2(3.3 \%)$ cases had bladder injury (Figure 2).

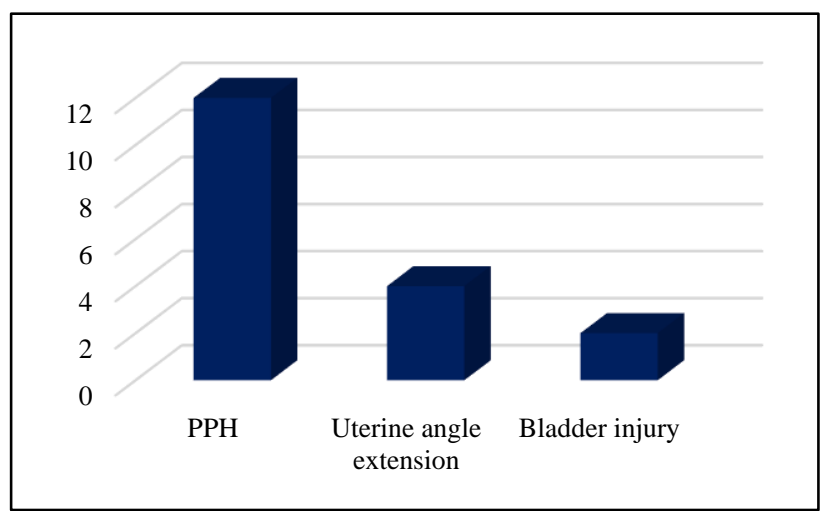

Figure 2: Intra operative complications.

\section{Postoperative complications}

The cases which required blood transfusion were 9 (15\%), febrile illness was $5(8.3 \%)$, wound infection was $2(3.3 \%)$ and prolong hospital stay more than 7 days were $16(26 \%)$ (Figure 3$)$.

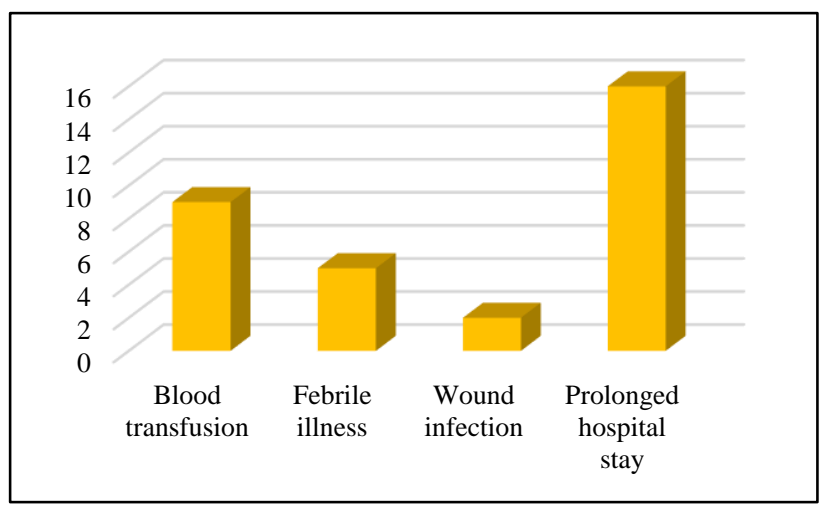

Figure 3: Post-operative complications.

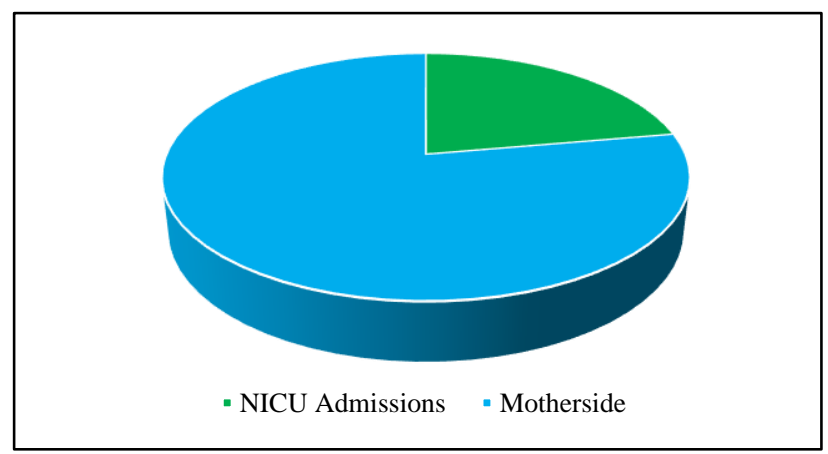

Figure 4: NICU admissions. 


\section{Neonatal outcome}

\section{NICU admissions}

NICU admissions $12(20 \%)$ as compared to babies shifted to mother side $42(80 \%)$ (Figure 4$)$.

\section{APGAR score}

Distribution in $2^{\text {nd }}$ stage LSCS patients. Normal APGAR seen in 46 (77\%), APGAR 7-9 seen in $7(11.6 \%)$ and $<7$ APGAR score seen in $5(8 \%)$ cases (Figure 5).

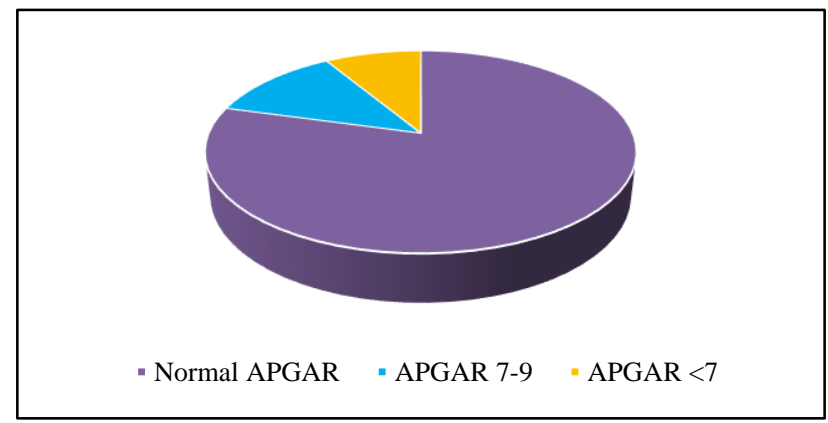

Figure 5: APGAR scores.

\section{DISCUSSION}

Most common indications for second stage LSCS in our study was fetal distress- 20 (33\%), arrest in descent- 15 (24\%), deflexed head- 11 (18\%), DTA- 9 (15\%), occipito posterior- $5(11 \%)$. According to Babre et al most common indications for $2^{\text {nd }}$ stage LSCS are fetal distress$31(50.8 \%)$ followed by non-descent- $20(32.7 \%)$, deep transverse arrest- 18 (29.5\%), deflexed head- 16 (26.2\%), occipito posterior- $1(1.6 \%)$ which had similar sample size. $^{7}$

In our study intraoperative complications were postpartum haemorrhage was $12(20 \%)$, uterine angle extension was $4(6.6 \%)$ and $2(3.3 \%)$ cases had bladder injury.

According to Babre et al intraoperative complications like post-partum haemorrhage was $5(8.2 \%)$, extension of uterine incision $2(3.3 \%)$, injury to bladder $1(1.6 \%)$ cases. $^{7}$

In post-operative period the cases which required blood transfusion were $9(15 \%)$, febrile illness was $5(8.3 \%)$, wound infection was $2(3.3 \%)$ and prolong hospital stay more than 7 days were 16 (26\%). According to Babre et al Post-operative febrile illness 12 (19\%), wound infection $5(8.2 \%)$ cases. $^{7}$ According to Moodly et al maternal outcome, $\mathrm{PPH}$ in $3(5.6 \%)$, wound infection in 1 $(1.8 \%)$, blood transfusion $7(13.2 \%)$, febrile illness 4 $(7.5 \%)$ of cases $^{8}$ In our study $<7$ APGAR score seen in 5 $(8 \%)$ cases. According to Moodly et al neonatal outcome APGAR $<5$ seen in 3 cases $(5.6 \%) .{ }^{8}$

\section{CONCLUSION}

Second stage LSCS is associated with a greater number of maternal and neonatal morbidity.

Adequate clinical exposure and appropriate training are essential for safe performance in second stage LSCS. Obstetrics trainees should have adequate supervised training opportunities in order to improve recognition of necessity for caesarean section at full dilatation.

Funding: No funding sources

Conflict of interest: None declared

Ethical approval: The study was approved by the Institutional Ethics Committee

\section{REFERENCES}

1. Cunningham FG, Lenovo KJ, Bloom SL, Dashe JS, Hoffman BL, Cassey BM, et al. William's text book obstetrics. 24th ed. Mc Graw Hill Medical Publishing Division; 2016.

2. Vousden N, Cargill Z, Briley A, Tydeman G, Shennan AH. Caesarean section at full dilatation: incidence, impact and current management. Obstet Gynaecol. 2014;16(3):199-205.

3. Unterscheider J, McMenamin M, Cullinane F. Rising rates of cesarean deliveries at full cervical dilatation: a concerning trend. Eur J Obstet Gynaecol Reprod Boil. 2011;157;141-4.

4. Panday GV. Second Stage caesarean section at a tertiary centre in South Africa. J Matern Fet Neonatmed. 2010;23(10)1151-5.

5. McKelvey A, Ashe R, McKenna D, Roberts R. Caesarean section in the second stage of labour: a retrospective review of obstetric setting and morbidity. J Obstet Gynaecol. 2010;30(3):264.

6. Singh S, Kohli UA, Vardhan S. Management of prolonged second stage of labor. Int J Reprod Contracept Obstet Gynecol. 2018;7(7):2527-31.

7. Babre VM, Bendre KR, Niyogi G. Review of caesarean sections at full dilatation. Int J Reprod Contracept Obstet Gynecol. 2017;6:2491-3.

8. Moodley J, Devjee J, Khedun SM, Esterhuizen T. Second-stage primary Caesarean deliveries: Are maternal complications increased? South Afr Fam Pract. 2009;51(4):328-31.

Cite this article as: Sailakshmi MPA, Vidhyadhare GS. Retrospective study of maternal and neonatal outcome in second stage lower segment caesarean section in a tertiary hospital. Int J Reprod Contracept Obstet Gynecol 2020;9:4924-6. 